\title{
Editorial
}

\section{Revista Alerta, cuatro años de retos y métricas de calidad}

\author{
DOI 10.5377/alerta.v4i3.12039 \\ Nadia Patricia Rodríguez Villalta \\ Instituto Nacional de Salud, Unidad de Gobernanza y Gestión del Conocimiento, San Salvador, El Salvador \\ Correspondencia \\ $\square$ amesol2005@gmail.com \\ (1) $0000-0002-2725-9210$
}

\section{ACCESO ABIERTO}

Revista Alerta, four years of challenges and quality metrics

\section{Citación recomendada: \\ Rodríguez-Villalta NP. Revista Alerta, cuatro años de retos y métricas de calidad. Alerta. 2021;4(3):90-91. DOI 10.5377/ alerta.v4i3.12039.}

Recibido:

8 de julio de 2021

Aceptado:

20 de julio de 202

Publicado:

26 de julio de 2021

Conflicto de intereses: La autora declara no tener conflicto de interés con ninguna organización.
En la historia de la humanidad han existido, entre otros acontecimientos importantes, dos hitos que han permitido que la ciencia avance y se desarrolle en gran escala. El primero de ellos, fue la escritura, que determinó el salto de la prehistoria' y el segundo se produjo a partir de la invención de internet, porque con este, además del intercambio de información y la conexión entre los investigadores de todo el mundo², se encauzó la digitalización de las publicaciones y se incrementó la colaboración internacional.

La difusión de las publicaciones en línea durante casi 20 años, ha permitido no solo la disminución de los costos, el incremento de su alcance, la rapidez en la divulgación de la evidencia científica y su reutilización ${ }^{1,2}$, sino también ha favorecido que el canal preferido para publicar los avances de la ciencia, sean las revistas científicas electrónicas. A pesar de ello, actualmente estos canales se diversifican cada vez más ${ }^{3}$, por tal razón, Alerta está desarrollando un plan de divulgación en redes sociales, con la finalidad de incrementar la visibilidad de sus publicaciones. Según datos de Google Analytics se han tenido 89756 usuarios en los últimos tres meses y los países que realizan mayor búsqueda orgánica son México (35,10\%), Perú (13,45\%), El Salvador (11,64\%), Ecuador (9,04\%) y Colombia (5,95\%).

Desde la creación de las primeras revistas en 1665, se habrían publicado hasta el 2010 unos 50 millones de artículos, sola- mente CrossRef distribuye cada año más de 97 millones de DOI a unas 60000 revistas'; esta magnitud trae aparejado un reto: saber discriminar con criterios y filtros de calidad las revistas y artículos relevantes.

Tradicionalmente, la calidad de las revistas se ha basado en la aceptación en índices de revistas científicas y el número de citas recibidas ${ }^{4,5}$, de hecho, para que las revistas sean atractivas a los autores deben ser incluidas en bases de datos como Web of Science (WOS) y Scopus 3 . Si bien es cierto, Alerta se encuentra indexada en sitios regionales relevantes como Lilacs, REDIB, AmeliCA, Latindex, MIAR (matriz de información para el análisis de revistas), Periódica y Clase, que ayudan a visibilizar las publicaciones de América Latina, queda un largo camino que seguir, en cumplimiento de las buenas prácticas de publicación, para llegar a «ser visibles globalmente»'.

Con relación al impacto, Alerta tiene un índice h de cinco. El artículo más citado es «introducción a los tipos de muestreo» ${ }^{6}$, con 40 citaciones y 120466 vistas, el número total de citas de los artículos publicados en Alerta asciende a 91, el año con más citaciones ha sido el 2021 con 36 citas (contabilizadas hasta julio de 2021), esto podría estar relacionado con la difusión en redes sociales.

Otro de los aspectos importantes dentro de las buenas prácticas para las revistas científicas ${ }^{7}$, es la endogamia. Esta tiene multiplicidad de acepciones, pero en este caso 
nos referimos a la endogamia institucional y editorial.

En sus comienzos en el año 2018, Alerta tuvo una endogamia del 55,5\%, es decir que la mayoría de sus manuscritos provenían del Instituto Nacional de Salud o de miembros del comité editorial, en el año 2019 disminuyó a 48 \% y alcanzó en el año 2020 el 27\% de endogamia. Se han invitado autores de otras instituciones y países y se crearon mecanismos para privilegiar el mérito científico del contenido, a través de una revisión objetiva, que limite los trabajos de editores o investigadores de la revista. Y es así que, durante el 2021, el $76 \%$ de los autores provenían de diferentes instituciones públicas y privadas del sector salud, es decir, que solo seis publicaciones fueron del Instituto Nacional de Salud (dos de éstas en coautoría con otras instituciones) y tres fueron publicaciones de miembros del comité editorial. Esto constituye un $24 \%$ de endogamia institucional y editorial. El tercero de los retos, para los suplementos venideros es incrementar la colaboración científica nacional e internacional.

Durante estos cuatro años se han recibido 150 manuscritos, de estos, se han publicado 99 , es decir un $66 \%$, con un promedio de 12,3 artículos publicados por suplemento. La revista tiene una tasa de rechazo de $34 \%$, de ellos un 9,3\% son rechazados por problemas éticos, técnicos o metodológicos, el 6,6\% es a causa de la declinación por parte de los autores y un $18 \%$ es por falta de respuesta o no cumplimiento de los tiempos editoriales.

Este año se han realizado 38 publicaciones, 15 corresponden a este número, de estas, el 55,3\% han sido originales, es decir, que se han publicado 21 artículos originales en el año, el incremento de las publicaciones, con relación a los años anteriores, se debe al número especial dedicado a $\mathrm{CO}$ VID-19. En los tres años anteriores el promedio de originalidad ha estado por encima del $59 \%$, el 2019 tuvo el porcentaje más alto de originalidad anual, con un $81 \%$.

Como parte de la mejora continua de la Revista Alerta se tienen metas a corto plazo, dentro de ellas están, continuar los procesos de indexación en índices y bases de datos reconocidos a nivel global, continuar con los incentivos para la publicación y los cursos de escritura de artículos científicos, cumplir con las buenas prácticas de publicación, como un porcentaje de endogamia menor al $25 \%$, incrementar la colaboración internacional y los trabajos en equipos in- terdisciplinarios. Los retos a mediano plazo son incrementar el impacto y desarrollar métricas de redes sociales, como Facebook y Twitter ${ }^{8}$, Google Data Studio entre otros, la traducción de Alerta al idioma inglés, y además seguir contribuyendo en la construcción de una cultura de investigación y de publicación local, que permita divulgar las contribuciones en español e inglés que genere impacto social y académico.

\section{Referencias bibliográficas}

1. Aliaga FM. Evolución de la edición científica en revistas de Ciencias Sociales y determinación de Latinoamérica como ecosistema característico. RELIEVE. 2020;26(2)1-20. https://doi.org/10.7203/ relieve.26.2.19206

2. Travieso Aguiar M. Las publicaciones electrónicas: una revolución en el siglo XXI. ACIMED. 2003;11(2):1-2. Disponible en: http://scielo.sld.cu/scielo. php?script=sci arttext\&pid=S102494352003000200001\&lng=es.

3. Dinu NR, Baiget T. Presente y futuro de las revistas científicas. Scire. 2019;25(1):37-46. Disponible en: https://www.ibersid.eu/ojs/ index.php/scire/article/view/4611/4235

4. Bojo Canales C, Sanz Valero J. Indicadores de impacto y prestigio de las revistas de ciencias de la salud indizadas en la Red SciELO: estudio comparativo. Rev Esp Salud Pública. 2020;94:(9)e1-12. Disponible: https://www.mscbs.gob.es/biblioPublic/ publicaciones/recursos propios/resp/ revista cdrom/VOL94/ORIGINALES/ RS94C 202009110ok.pdf

5. Cortés Vargas D. Medir la producción científica de los investigadores universitarios: la bibliometría y sus límites. Rev. Edu. Sup. 2007;36(142):43-65. Disponible en: https://www.redalyc.org/ articulo.oa?id=60414203

6. Hernández Ávila CE, Carpio N. Introducción a los tipos de muestreo. Revista Alerta. 2019;2(1):75-79. DOI: 10.5377/alerta. v2i1.7535

7. Guía de buenas prácticas para revistas académicas de acceso abierto. ONG Derechos Digitales. Santiago de Chile, Chile. 2011. Disponible en: https://latindex.org/lat/ documentos/descargas/Manual-Buenas Practica Revistas Academicas.pdf

8. Wang D, László Barabási A. The Science of Science. 1st. Edition. England. Cambridge University Pres Ed.; 2021. 275 p. 